\title{
Peran Kesetaraan Gender di Masa Pandemi
}

\author{
${ }^{1)}$ Erny Hutabarat, ${ }^{2)}$ Danielle Nadine Anakotta, ${ }^{3)}$ Xie Haozhe \\ 1) Program Studi Manajemen, Universitas Presiden, ernyhutabarat@president.ac.id \\ 2) Program Studi Manajemen, Universitas Presiden, danielleanakotta@gmail.com \\ 3) Program Studi Manajemen, Universitas Presiden, xie.haozhe@student.president.ac.id
}

\begin{abstract}
ABSTRAK
Di masa pandemi ini banyak sekali isu-isu sosial yang terbengkalai karena kondisi yang memaksa. Salah satu isu yang mulai terbengkalai adalah kesetaraan gender. Kegiatan Pengabdian kepada Masyarakat (PKM) yang berjudul 4space.foryou ini mengedukasi pengikut (follower) untuk mengetahui pentingnya kesetaraan gender dan bentuk-bentuk dari diskriminasi gender di masa pandemi ini. Oleh karena itu, tujuan dari program ini adalah untuk mengedukasi dan meningkatkan kesadaran tentang pentingnya menjunjung tinggi kesetaraan gender. Metode yang digunakan adalah membuat kampanye di Instagram dengan mengangkat 3 topik utama, yaitu toxic masculinity, pemisahan pekerjaan, dan wanita karir \& pria rumah tangga. Program ini dilaksanakan bekerjasama dengan seorang content creator, Iwan Kurniawan. Program kampanye 4space.foryou ini berhasil mendapatkan 100 partisipan dan berhasil memberi pengaruh kepada pengikut melalui konten yang disajikan. Program ini juga berhasil membawa pengaruh bagi Iwan Kurniawan dan pengikutnya di Instagram. Secara keseluruhan program ini dapat dikatakan berhasil, terbukti bahwa sebagian besar pengikut menyatakan bahwa materi dan disain yang ditampilkan menarik dan sangat menarik.
\end{abstract}

Kata-kata Kunci: Mengedukasi, Kesetaraan Gender, Toxic Masculinity,

Pemisahan Pekerjaan, Wanita Karir \& Pria Rumah Tangga

\begin{abstract}
During this pandemic, there are many issues that have been neglected due to compelling conditions. One of the issues that has begun to be neglected is gender. Through the 4space.foryou, this program educates followers to know about gender and the forms of gender discrimination during this pandemic. The aim of this program is to educate and bring awareness about the forms that respect gender. The method is creating a campaign on Instagram with 3 main topics, toxic masculinity, job separation, and career woman \& househusband. This program is also cooperated with a content creator, named Iwan Kurniawan. This program has succeeded in bringing influence to Iwan Kurniawan and his followers on Instagram. Overall, this program can be said to be successful. Most of the followers stated that the materials and designs displayed were interesting and very interesting.
\end{abstract}

Keywords: Educate, Gender Equality, Toxic Masculinity, Job Separation, Career Woman \& Househusband

\section{PENDAHULUAN}

Berdasarkan riset, kesetaraan gender adalah masalah umum di Indonesia namun sampai saat ini belum terselesaikan. Di Indonesia masih ditemukan banyak kasus diskriminasi terkait gender. Hal ini dapat dilihat bahwa indeks kesetaraan gender Indonesia berada pada peringkat 103 dari 162 negara (Winahyu, 2020). Di masa Pandemi Covid-19, isu ini menjadi agak terbengkalai karena kondisi yang memaksa demikian.

Melihat kondisi tersebut, dosen dan sejumlah mahasiswa Universitas Presiden bekerjasama dengan seorang content creator bernama Iwan Kurniawan memprakarsai sebuah kegiatan Pengabdian kepada Masyarakat (PKM) yang berjudul 4space.foryou. Iwan Kurniawan adalah pemilik akun @belajarcarabelajar, sebuah akun berisi tentang bagaimana belajar secara efektif dengan alat yang tepat dan cara yang benar. 
Tujuan kegiatan PKM ini adalah mengedukasi pengikut (follower) Instagram @4space.foryou serta pengikut Instagram Iwan Kurniawan tentang pentingnya kesetaraan gender dan isu-isu yang sedang muncul, khususnya di masa Pandemi Covid-19. Selanjutnya @4space.foryou akan menjadi sub-Instagram dari @belajarcarabelajar yang fokus menjelaskan isi dan subtopik kesetaraan gender. Di feed Instagram @4space.foryou diposting informasi tentang kesetaraan gender setiap minggu. Program ini juga membuat sorotan di Instagram tentang setiap sub-topik dan memposting snapgram yang dapat berinteraksi secara langsung dengan pengikut Instagram @4space.foryou.

Melalui kegiatan ini diharapkan @4space.foryou dapat memengaruhi remaja untuk menyadari isu-isu penting terkait kesetaraan gender. Manfaat lainnya adalah menarik orang lain untuk mengikuti pembelajaran di @belajarcarabelajar, mendapatkan inspirasi untuk konten postingan, meningkatkan kesadaran kesetaraan gender di masa pandemi, mendidik masyarakat tentang sub topik kesetaraan gender, dan memberikan solusi bagaimana seharusnya remaja mengatasi diskriminasi serta mengubah cara pandangnya.

Mengingat media sosial adalah platform yang sangat populer di kalangan Generasi $Z$, maka media sosial digunakan sebagai platform dalam proses edukasi ini, yaitu melalui Instagram.

\section{METODE PELAKSANAAN}

\subsection{Deskripsi Singkat}

Program ini bekerjasama dengan seorang content creator di Instagram bernama Iwan Kurniawan dan akun Instagramnya @belajarcarabelajar (Kurniawan, 2021). Program ini juga berkolaborasi dengan akun-akun lainnya untuk berbagi informasi tentang kesetaraan gender di Indonesia. Jenis konten mitra kegiatan ini adalah untuk berbagi informasi tentang cara efektif dalam mempelajari sesuatu. Program ini akan membagikan postingan yang cakupannya lebih dalam tentang kesetaraan gender daripada di @belajarcarabelajar. Akun Instagram @4space.foryou memecah kesetaraan gender menjadi 3 sub topik, yaitu toxic masculinity, pemisahan pekerjaan, dan wanita karir \& pria rumah tangga. @4space.foryou memposting 6 feed Instagram untuk setiap sub-topik dan 2 slide snapgram yang berisikan rangkuman setiap materi. Program ini juga membuat snapgram yang dapat berinteraksi secara langsung dengan follower Instagram @4space.foryou serta @belajarcarabelajar melalui kuis atau polling. Pada setiap materi yang sudah dkupas, dibuatkan sorotan khusus terkait materi tersebut di Instagram @4space.foryou.

\subsection{Sasaran Kegiatan/Peserta}

Kegiatan ini ditargetkan menarik lebih kurang 2.000 pengikut dari Instagram @belajarcarabelajar, yang terdiri dari generasi milenial (usia 25-40 tahun dengan profesi 
sebagai pegawai, wiraswasta, dan PNS) dan generasi Z (usia 9-24 tahun, dengan profesi pelajar, mahasiswa).

\subsection{Tahapan Kegiatan}

Gambar 1 menunjukkan tahapan kegiatan, dimulai dari penelusuran dan pengumpulan materi hingga posting konten di akun instragram, baik pada akun @belajarcarabelajar maupun pada akun @4space.foryou. Masing-masing materi dari 3 sub-topik kesetaraan gender dibuat 6 postingan, sehingga secara total terdapat 18 postingan. Materi-materi tersebut diambil dari berbagai sumber sebagaimana dicantumkan pada Referensi. Setelah semua materi siap, selanjutnya dilakukan editing disain agar menarik feed dan instastory.

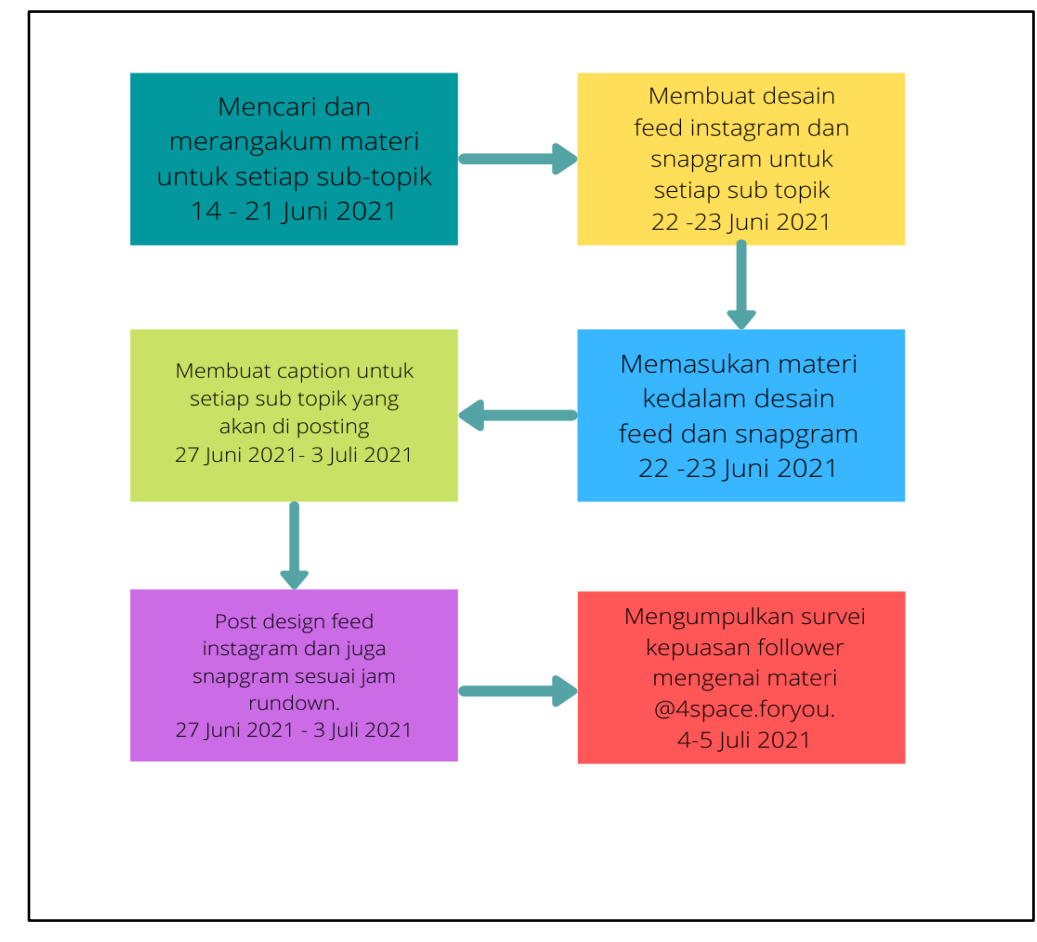

Gambar 1.

Tahapan Kegiatan 4space.foryou

\subsection{Jadwal dan Pelaksana Kegiatan}

Kegiatan ini dilaksanakan pada Semester Genap 2020/2021, yaitu pada bulan MeiJuli 2021. Pada bulan Mei 2021 dilakukan persiapan program yang meliputi penentuan materi dan kemungkinan kerjasama dengan pihak lain. Kampanye dan edukasi dilaksanakan pada bulan Juni dan Juli 2021. Jadwal kegiatan secara lengkap dapat dilihat pada Lampiran 1. Pelaksana kegiatan ini adalah dosen dan mahasiswa Universitas Presiden, sebagaimana terlihat pada Lampiran 2. 


\subsection{Faktor Pendukung dan Tantangan}

Berikut adalah faktor pendukung dari program ini:

1. Program ini memiliki sekitar 2000 pengikut yang dapat dipengaruhi melalui @belajarcarabelajar.

2. Progam ini dapat dilakukan secara online, sehingga dapat mempraktikkan jarak sosial pada masa pandemi.

3. Progam ini dapat menggunakan media sosial yang berarti dapat berbagi ide dengan orang lain dan melibatkan banyak orang dari berbagai daerah dan lintas budaya.

4. Program ini dapat dengan mudah meminta feedback tentang konten Instagram @4space.foryou dengan menanyakan pengikut @belajarcarabelajar dengan membuat polling di snapgram.

Berikut adalah faktor tantangan dari program ini:

1. Sulit bagi program ini untuk membuat konten yang bagus di feed Instagram atas setiap topik untuk mudah dipahami oleh pengikut @belajarcarabelajar.

2. Tidak mudah untuk membuat disain untuk setiap topik.

3. Tidak mudah untuk terus berinteraksi dengan pengikut @belajarcarabelajar dengan membuat snapgram interaktif.

4. Tidak mudah bagi program ini untuk menarik pengikut @belajarcarabelajar memperhatikan Instagram @4space.foryou sebagai tempat mereka mempelajari materi yang diberikan.

\section{HASIL DAN PEMBAHASAN}

\subsection{Perkenalan @4space.foryou}
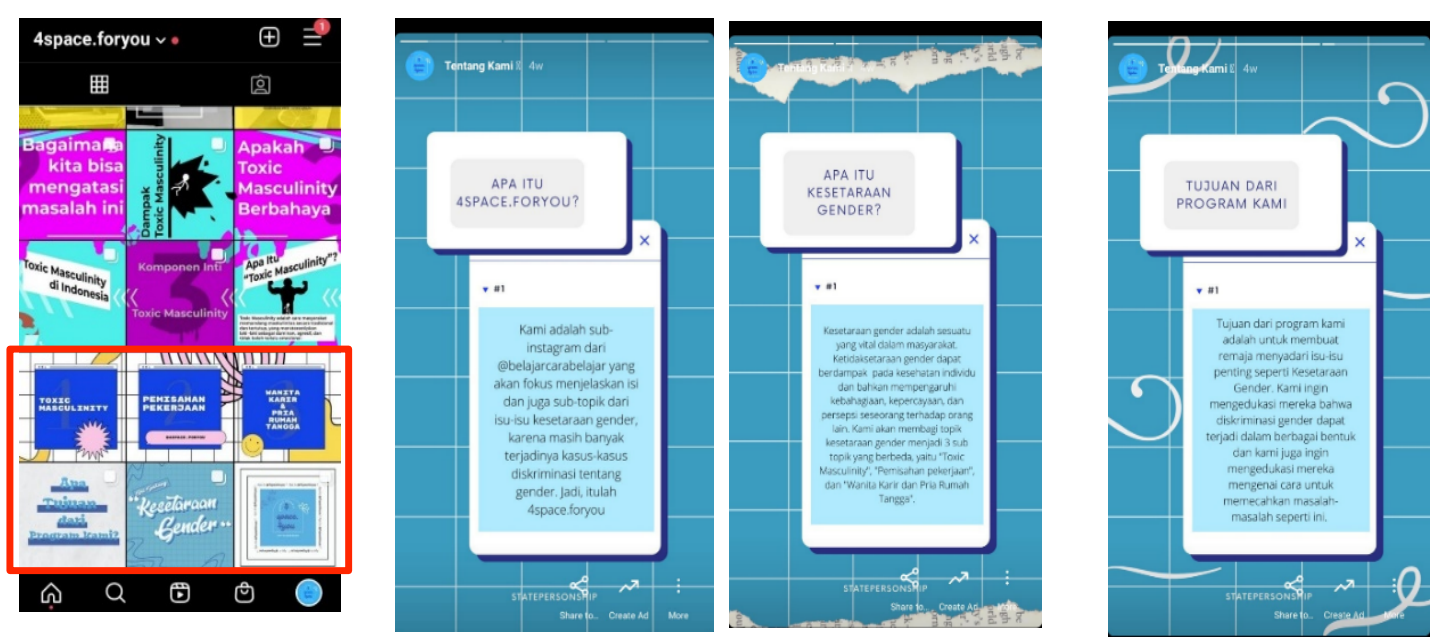

Gambar 2.

Unggahan Materi Pengenalan 4space.foryou 
Langkah pertama adalah memperkenalkan @4space.foryou dan memperkenalkan topik utama yang dibahas yaitu kesetaraan gender yang dibagi menjadi 3 sub-topik (lihat Gambar 2 dan Gambar 3).
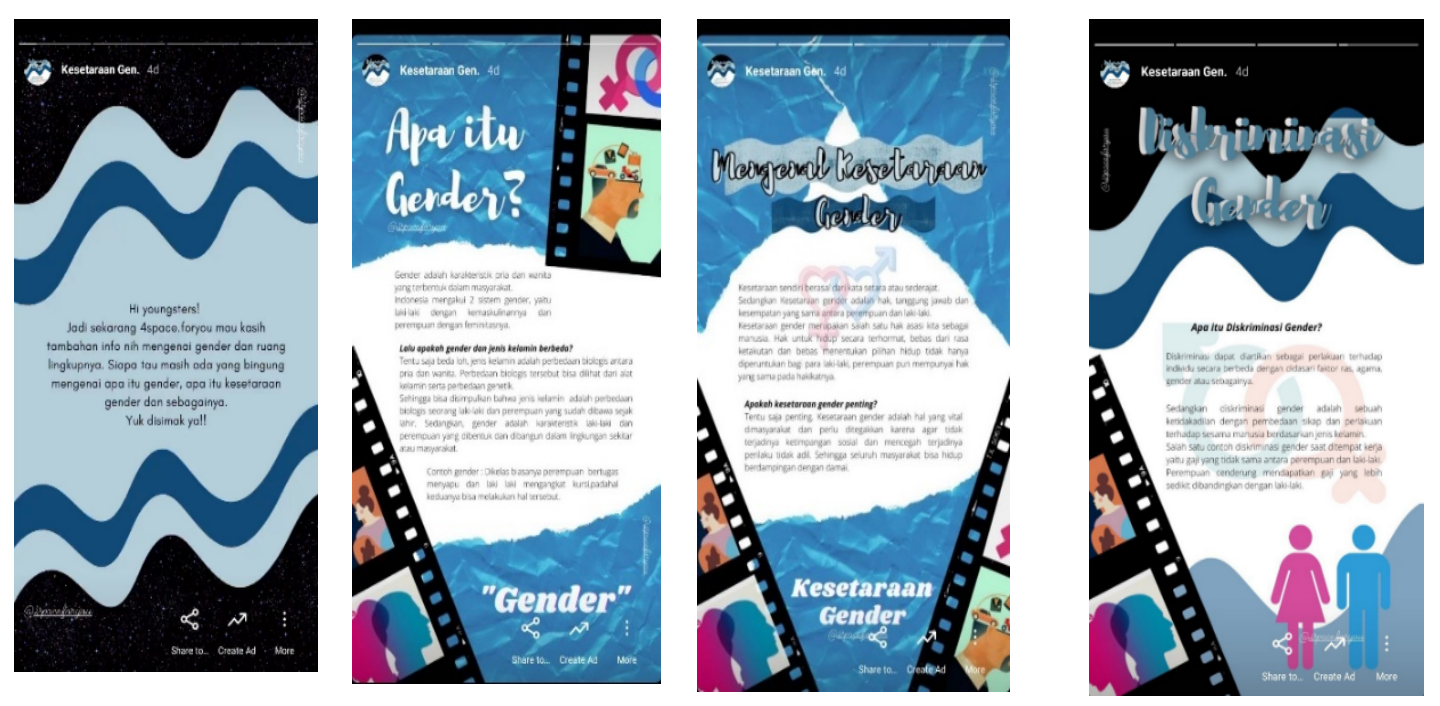

Gambar 3.

Unggahan Materi Kesetaraan Gender

\subsection{Mengunggah Materi Toxic Masculinity}

Kegiatan kedua adalah mengunggah 3 materi tentang toxic masculinity, yang berisi definisi, 3 komponen inti, dan contohnya di Indonesia (lihat Gambar 4). Unggahan keempat adalah tentang bahaya/masalah yang ditimbulkan oleh toxic masculinity. Unggahan kelima menjelaskan 3 dampak dari toxic masculinity, yaitu kekerasan dan agresi terhadap manusia, kurangnya perilaku membantu, dan kekhawatiran kesehatan mental. Unggahan keenam menjelaskan bagaimana anak muda dapat mengatasi masalah-masalah tersebut.
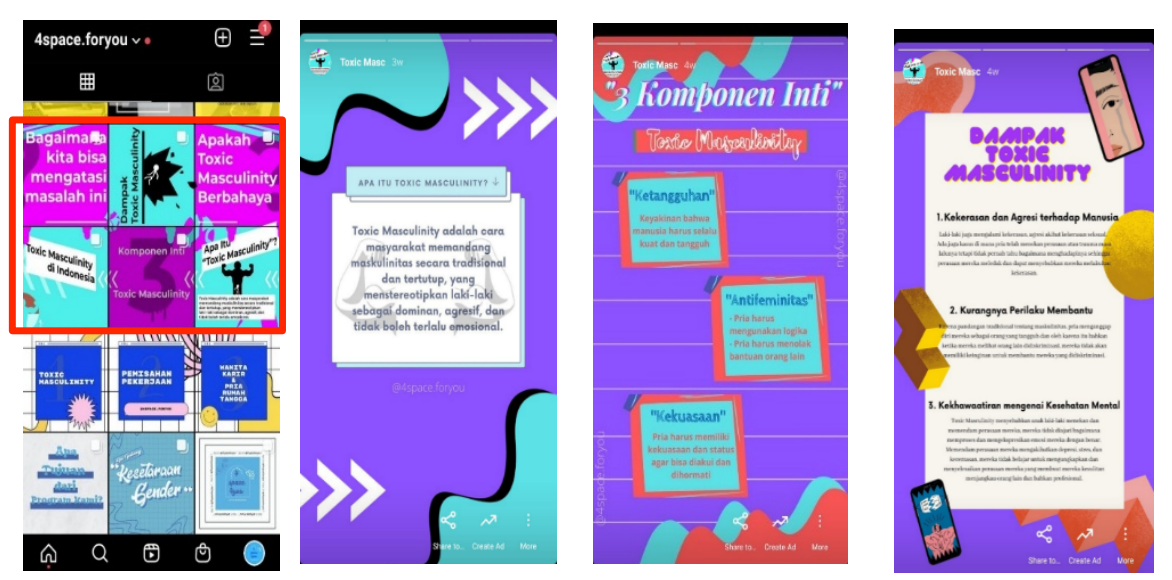

Gambar 4.

Unggahan Materi Toxic Masculinity 


\subsection{Mengunggah Materi Pemisahan Pekerjaan}

Unggahan pertama adalah tentang definisi dari pemisahan pekerjaan. Unggahan kedua adalah contoh pemisahan pekerjaan secara umum, yang terbagi menjadi 3 yaitu pemisahan gender berdasarkan industri, pekerjaan, dan peran dalam organisasi. Unggahan ketiga adalah mengenai contoh pemisahan pekerjaan di Indonesia. Hal ini bertujuan agar para pembaca semakin paham dengan contoh kasus yang telah terjadi di Indonesia yang mungkin saja terjadi juga di lingkungan sekitar pembaca. Unggahan keempat mengenai mengapa pekerjaan dipisahkan berdasarkan gender atau faktor terjadinya pemisahan pekerjaan. Unggahan kelima membahas mengenai dampak dari pemisahan pekerjaan. Hal ini bertujuan agar pembaca menyadari apa saja akibat yang terjadi dari kasus pemisahan pekerjaan sehingga pemikiran pembaca bisa lebih terbuka terhadap isu-isu gender. Unggahan keenam membahas bagaimana cara mengatasi pemisahan pekerjaan (lihat Gambar 5).
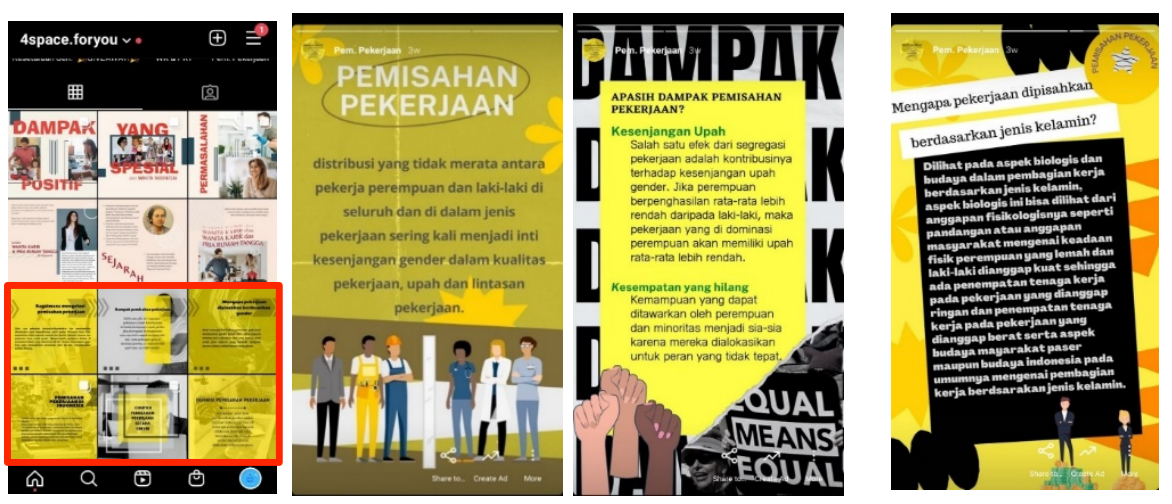

Gambar 5.

Unggahan Materi Pemisahan Pekerjaan

\subsection{Mengunggah Materi Wanita Karir \& Pria Rumah Tangga}
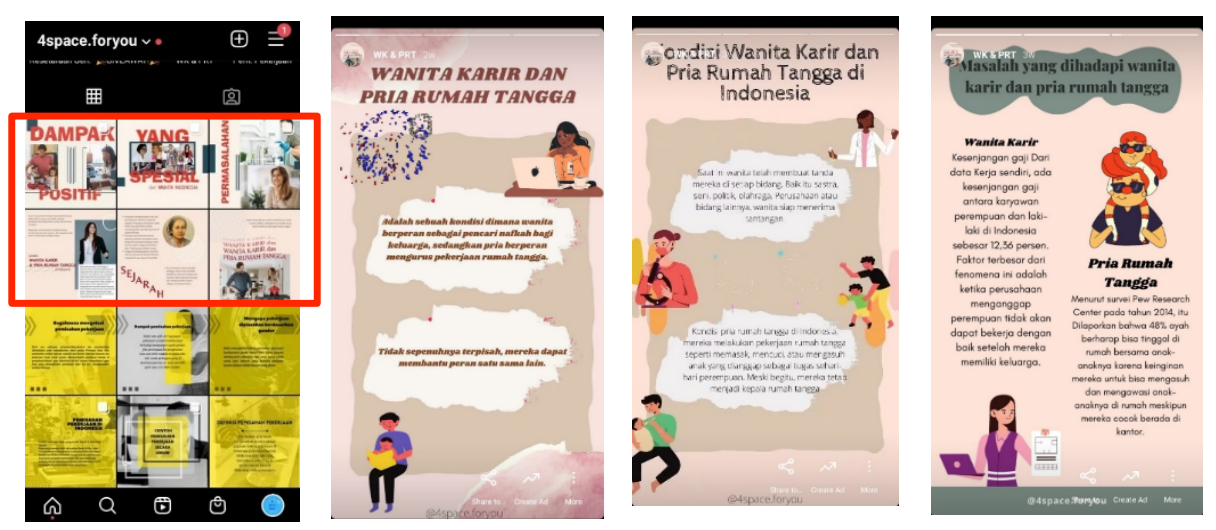

Gambar 6.

Unggahan Materi Wanita Karir \& Pria Rumah Tangga 
Materi wanita karir \& pria rumah tangga mencakup 6 bahasan, yaitu pengertian tentang wanita karir \& pria rumah tangga, sejarah wanita karir, kondisi wanita karir \& pria rumah tangga, permasalahan yang timbul akibat wanita karir \& pria rumah tangga, dampak positif, dan yang spesial dari wanita Indonesia (lihat Gambar 6).

\subsection{Menggungah Materi Giveaway}

Setelah memposting semua materi mengenai kesetaraan gender, selanjutnya adalah memposting giveaway bagi pengikut @4space.foryou beserta syarat-syaratnya. Untuk mengikuti giveaway, partisipan mengisi G-form yang berisi pertanyaan tentang materi (lihat Gambar 7). Pemenang adalah mereka yang memberikan jawaban terbaik atas pertanyaan yang diberikan melalui G-form mengenai hal-hal yang mereka dapatkan setelah membaca materi yang diunggah. Terdapat 3 (tiga) orang pemenang yang masing-masing berhak mendapatkan uang sebesar $\operatorname{Rp} 60.000,00$.
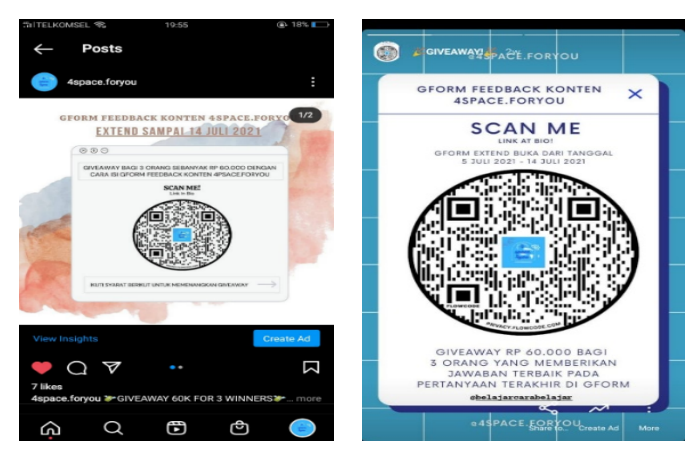

Gambar 7.

Unggahan Materi Giveaway di Feed Instagram dan Instastory

\subsection{Evaluasi Kegiatan}

Evaluasi dilakukan dengan menyediakan kuesioner melalui G-form yang berisi pertanyaan antara lain:

1. Apakah materi di @4space.foryou mengenai kesetaraan gender relevan dengan kondisi dunia saat Ini? (Ya/Tidak)

2. Apakah materi di @4space.foryou menarik? (1-5: Tidak Menarik - Sangat Menarik)

3. Apakah disain materi di @4space.foryou menarik? (1-5: Tidak Menarik - Sangat Menarik)

4. Dari 3 sub topik (toxic masculinity, pemisahan pekerjaan, dan wanita karir \& pria rumah tangga), manakah yang sangat bermanfaat?

5. Apa yang dapat ditingkatkan dari materi yang disampaikan pada @4space.foryou? 
6. Apa saja diperoleh setelah membaca sub-topik pada @4space.foryou tentang kesetaraan gender? (3 jawaban terbaik akan mendapatkan giveaway sebanyak Rp $60.000,00)$

Kuesioner ini diisi oleh 100 responden, dengan profil sebagaimana terlihat pada Gambar 8.

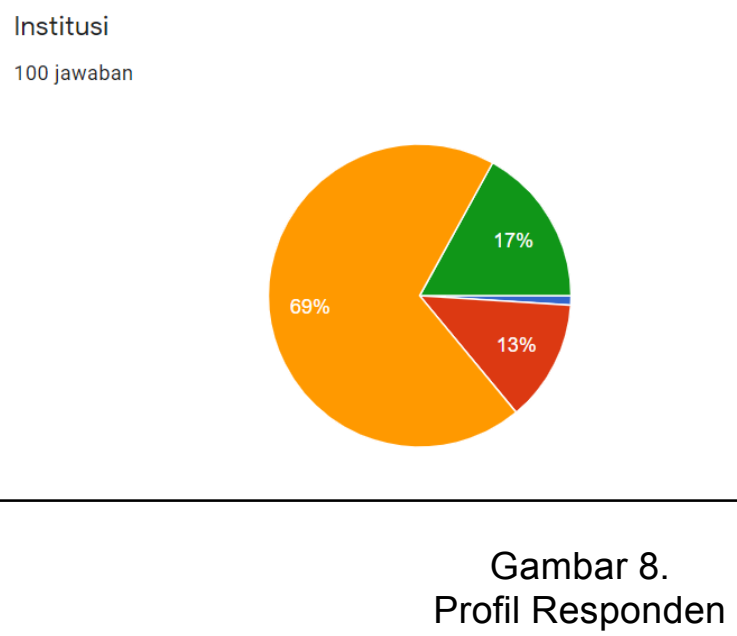

Gambar 8.

Profil Responden

Terkait dengan materi dan disain materi, pada umumnya responden menyatakan menarik dan sangat menarik (lihat Gambar 9 dan 10). Terkait dengan 3 (tiga) sub-topik yang paling menarik menurut responden, di posisi yang pertama adalah toxic masculinity $(40 \%)$, kedua wanita karir \& pria rumah tangga (31\%), dan pemisahan pekerjaan $(22 \%)$. Sedangkan $7 \%$ lainnya menjawab ketiganya menarik.

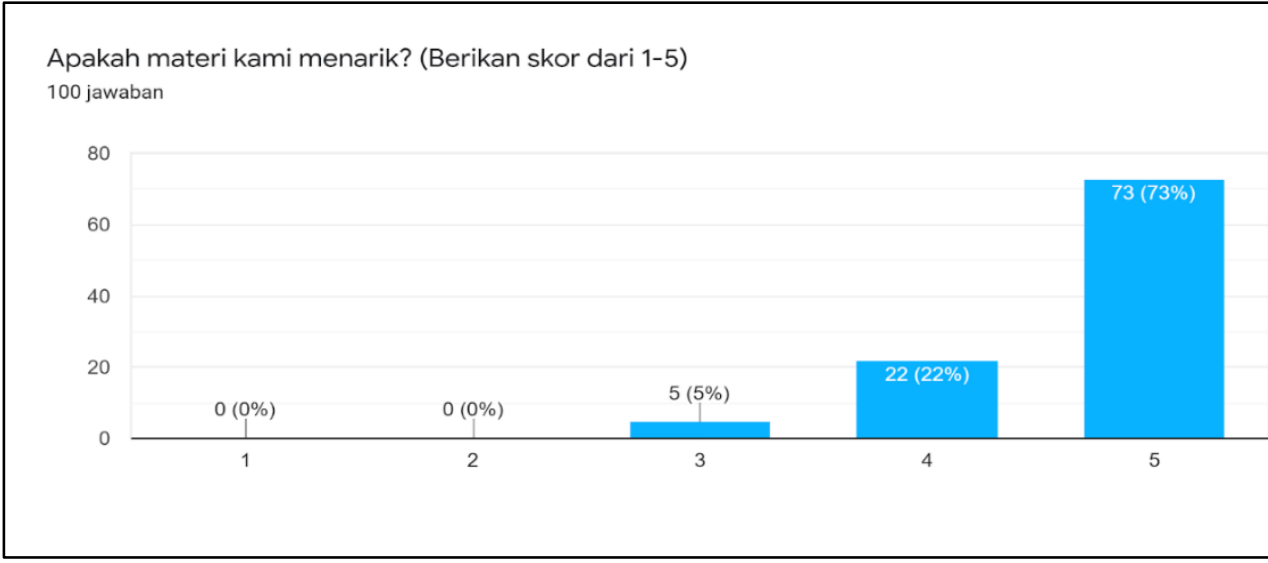

Gambar 9.

Tanggapan Responden atas Materi 


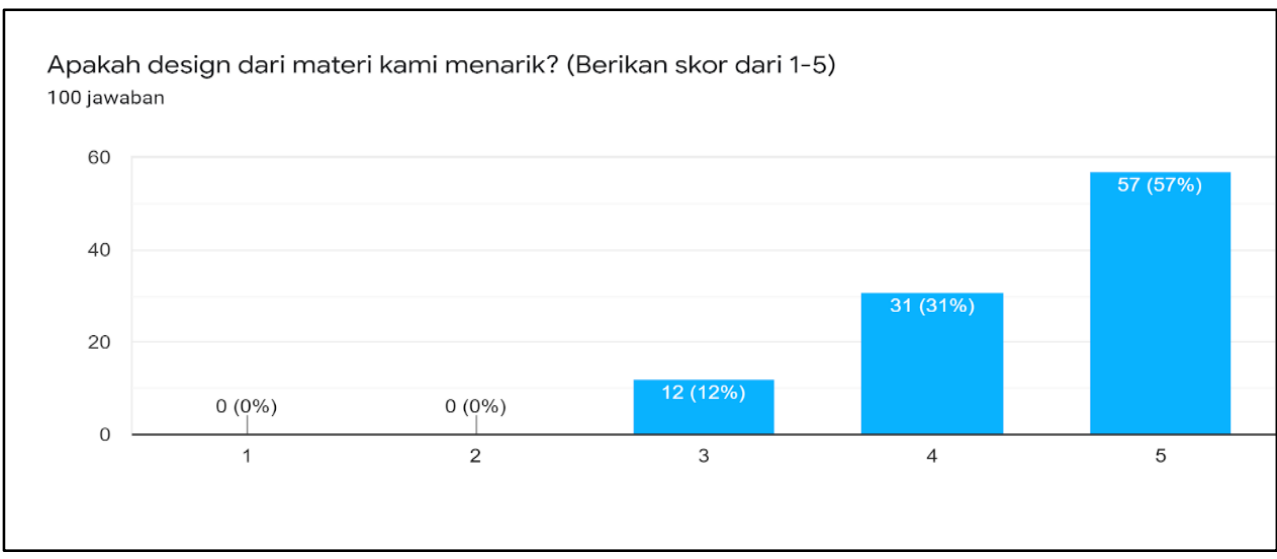

Gambar 10.

Tanggapan Responden atas Disain Materi

Responden juga banyak mendapatkan hal positif dari topik-topik yang diberikan. Salah satunya mengungkapkan bahwa, "Akun instagram ini memberikan edukasi tentang kesetaraan gender, yang dimana jika saya riset di instagram, masih jarang content creator yang menjelaskan tentang ini, sehingga ini peluang yang sangat bagus untuk diteruskan. Lalu kesetaraan gender ini juga menarik dan banyak dibutuhkan masyarakat karena di Indonesia masih banyak problem terkait ini. Saya juga belajar banyak setelah mengetahui akun ini, karena tiap kontennya dijelaskan cukup detail, simple, dan disainnya juga sangat enak diliat sehingga enjoy buat dibaca kontennya".

Selain itu, ada responden yang menyarankan beberapa hal yang bertujuan untuk meningkatkan kualitas, menambahkan video untuk membuat pandangan followers semakin tertarik dan memperluas cakupan materi untuk memperdalam pemahaman tentang kesetaraan gender.

\subsection{Saran dari @belajarcarabelajar}

Selain feedback dari audience @4space.foryou, diperoleh juga feedback dari pemilik@belajarcarabelajar sebagai berikut:

1. Tujuan mengedukasi audience tercapai dengan baik. Kegiatan ini mampu meningkatkan pengetahuan dan kepedulian para followers kedua akun (@4space.foryou dan @belajarcarabelajar) tentang kesetaraan gender, khususnya bagi anak muda zaman sekarang yang sangat aktif di sosial media.

2. Kinerja tim sangat baik karena informatif, cepat tanggap dan selalu memberi penjelasan tentang materi yang dibahas dengan detail. Disamping itu, disain-disain yang dibuat dinilai sangat eye catching dan menarik audience untuk melihat lebih dalam lagi. 
3. Dalam rangka mengembangan akun @4space.foryou, disarankan untuk memperdalam pembahasan tentang kesetaraan gender agar audience lebih banyak mendapatkan insight dengan menampilkan materi yang benar-benar jarang dibahas di masyarakat. Disamping itu juga dapat memuat game berupa quiz atau poll di instastory agar dapat berinteraksi lebih intensif dengan audience.

\section{KESIMPULAN}

Upaya 4space.foryou untuk menarik perhatian kalangan muda Indonesia dapat dikatakan berhasil. Hal ini terlihat dari banyaknya responden yang merupakan followers, viewers, dan juga peserta campaign giveaway. Para pemenang campaign giveaway dan peserta lainnya dapat dipastikan merasa tertantang untuk dapat berpikir sekritis mungkin untuk merespon konten-konten yang diberikan terkait materi toxic masculinity, pemisahan pekerjaan, serta wanita karier \& pria rumah tangga.

Bukti lain keberhasilan kegiatan ini adalah adanya saran terkait perbaikan, upgrade, dan penambahan konten di akun sosial media @4space.foryou. Hal ini menunjukkan adanya potensi bahwa @4space.foryou dapat menjadi awareness agent bagi kalangan muda yang aktif di sosial media. Oleh karena itu 4space.foryou dapat terus mengembangkan kemampuannya dalam mengumpulkan informasi, memasak konten sosial media, dan juga keterampilan visualisasi konten untuk menyediakan konten yang bertemakan social problems dan isu-isu lainnya. Satu hal yang penting adalah selalu berkembang dalam jalan yang baik dan benar, dan tidak pernah berhenti untuk menciptakan yang terbaik bagi diri sendiri dan juga bagi semua orang.

\section{REFERENSI}

Arifin, R. D. 2020. Pengertian Facebook beserta Sejarah, Manfaat, Kelebihan, Kekurangan. Diunduh dari: https://dianisa.com/pengertian-facebook/

Farkhani, N. F. 2014. Bicara Soal Wanita, Wanita Karir, Dampak Negatif Wanita Karir Diunduh dari:

https://www.kompasiana.com/www.nabilahfirda.com/54f93a26a33311b6078b48e9/bica ra-soal-wanita-wanita-karir-dampak-negatif-wanita-karir

Freeman, O. (n.d.). Why Is Equality Important? - Life The Freeman Online. Diunduh dari: https://www.thefreemanonline.org/why-is-equality-important/

Kaplan, A. M. 2015. Social Media, the Digital Revolution, and the Business of Media. International Journal on Media Management, 17(4), 197-199. https://doi.org/10.1080/14241277.2015.1120014

Khalidza, T. 2018. Kesetaraan Gender yang Belum Merata di Indonesia. Diunduh dari: https://kumparan.com/trisia-khalidza/kesetaraan-gender-yang-belum-merata-di- 
indonesia/full

Kurniawan, I. (n.d.). Iwan | Edukasi Belajar (@belajarcarabelajar)•Instagram photos and videos. Diunduh dari: https://www.instagram.com/belajarcarabelajar/

Morin, A. 2020. What Is Toxic Masculinity? Diunduh dari: https://www.verywellmind.com/what-is-toxic-masculinity-5075107

P-3. A. 2017. Pancasila Tenggelam di Era Reformasi. Diunduh dari: https://mediaindonesia.com/politik-dan-hukum/130156/pancasila-tenggelam-di-erareformasi

Rights Commission, A. H. 2017. Gender segregation in the workplace and its impact on women's economic equality | Australian Human Rights Commission. Diunduh dari: https://humanrights.gov.au/our-work/legal/submission/gender-segregation-workplaceand-its-impact-womens-economic-equality

Winahyu, A. I. .2020. Kesetaraan Gender di Indonesia Masih Rendah. Diunduh dari: https://mediaindonesia.com/humaniora/351154/kesetaraan-gender-di-indonesia-masihrendah

Lampiran 1. Rundown Program

\begin{tabular}{|l|l|l|l|}
\hline \multicolumn{1}{|c|}{ No } & Tanggal & J a $\mathbf{~}$ & \multicolumn{1}{|c|}{ Materi } \\
\hline 1. & $25 / 06 / 21$ & 13.00 & Introduksi apa itu 4space.foryou \\
\hline 2. & $25 / 06 / 21$ & 13.00 & Introduksi topik utama: Kesetaraan Gender \\
\hline 3. & $25 / 06 / 21$ & 13.00 & Pengenalan mengenai tujuan program kami \\
\hline 4. & $25 / 06 / 21$ & 13.00 & 3 sub-topik yang akan dibahas \\
\hline 5. & $27 / 06 / 21$ & 10.00 & Defnisi tentang Toxic Masculinity \\
\hline 6. & $27 / 06 / 21$ & 10.00 & 3 komponen inti dari Toxic Masculinity \\
\hline 7. & $27 / 06 / 21$ & 10.00 & Toxic Masculinity di Indonesia \\
\hline 8. & $27 / 06 / 21$ & 11.00 & Apakah Toxic Masculinity berbahaya \\
\hline 9. & $27 / 06 / 21$ & 11.00 & Dampak Toxic Masculinity \\
\hline 10. & $27 / 06 / 21$ & 11.00 & Bagaimana cara kita memecahkan masalah ini \\
\hline 11 & $30 / 06 / 21$ & 10.00 & Definisi pemisahan pekerjaan \\
\hline 12 & $30 / 06 / 21$ & 10.00 & Contoh pemisahan pekerjaan secara umum \\
\hline 13 & $30 / 06 / 21$ & 10.00 & Pemisahan pekerjaan di Indonesia \\
\hline 14 & $30 / 06 / 21$ & 11.00 & $\begin{array}{l}\text { Mengapa pekerjaan dipisahkan berdasarkan jenis } \\
\text { kelamin }\end{array}$ \\
\hline 15 & $30 / 06 / 21$ & 11.00 & Dampak pemisahan pekerjaan \\
\hline & & & \\
\hline 15 & & & \\
\hline
\end{tabular}


Volume 3, Number 1, 2021, 46-57

\begin{tabular}{|l|c|c|l|}
\hline 16 & $30 / 06 / 21$ & 11.00 & Bagaimana mengatasi pemisahan pekerjaan \\
\hline 17 & $3 / 07 / 21$ & 10.00 & $\begin{array}{l}\text { Pengantar/Pengertian Wanita Karir dan Pria Rumah } \\
\text { Tangga }\end{array}$ \\
\hline 18 & $3 / 07 / 21$ & 10.00 & Rekam Jejak (Sejarah) Karir Wanita di Indonesia \\
\hline 19 & $3 / 07 / 21$ & 10.00 & $\begin{array}{l}\text { Kondisi Fenomena Wanita Karir dan Pria Rumah } \\
\text { Tangga di Indonesia }\end{array}$ \\
\hline 20 & $3 / 07 / 21$ & 11.00 & $\begin{array}{l}\text { Dampak Positif dan Negatif wanita karir dan pria } \\
\text { rumah tangga }\end{array}$ \\
\hline 21 & $3 / 07 / 21$ & 11.00 & $\begin{array}{l}\text { Masalah yang dihadapi wanita karir dan pria rumah } \\
\text { tangga }\end{array}$ \\
\hline 22 & $3 / 07 / 21$ & 11.00 & \begin{tabular}{l} 
Yang spesial dari wanita Indonesia \\
\hline 23
\end{tabular} \\
$\begin{array}{c}4 / 07 / 21 \\
-\end{array}$ & 10.00 & $\begin{array}{l}\text { Mengumpulkan survey kepuasan dari follower } \\
\text { @belajarcarabelajar and @4space.foryou. }\end{array}$ \\
\hline
\end{tabular}

Lampiran 2. Struktur Organisasi Pelaksana Kegiatan

\author{
Pembimbing I \\ Pembimbing II \\ Ketua Pelaksana \\ Wakil Ketua Pelaksana \\ Sekretaris \\ Bendahara \\ Penyelenggara Acara
}

Hubungan Masyarakat Internal

Eksternal Humas

Multimedia and Desain
: Ir. Erny Hutabarat, MBA

: Dr. Dedi Rianto Rahadi, MM.

: Danielle Nadine Anakotta MGT 2020

: Satryo Adi Antares VCD 2020

: Xie Haozhe MGT 2020

: Xu Han MGT 2020

: Edward Barent B. S.K. MGT 2020

Samuel Andrew Santoso MGT 2020

Antonius Chaesar N.P. VCD 2020

: Marcella Koesmadjie MGT 2020

Fauziah Aziz

Aisy Zalfaa

: Mutiara Safna

MGT 2020

VCD 2020

MGT 2020

Gede Abhie Septia W. VCD 2020

: Rangga Ary Sanjaya VCD 2020

Iman Alfarizi 